Article

\title{
Amplified Fluorescent Aptasensor for Ochratoxin A Assay Based on Graphene Oxide and RecJ $J_{\mathrm{f}}$ Exonuclease
}

\author{
Han Zhao ${ }^{\dagger}$, Dehui Xiong ${ }^{\dagger}$, Ying Yan and Changbei Ma * \\ School of Life Sciences, Central South University, Changsha 410013, China; zhaohan202010@163.com (H.Z.); \\ xiongdehui@csu.edu.cn (D.X.); Yany2018@csu.edu.cn (Y.Y.) \\ * Correspondence: macb2012@csu.edu.cn \\ + These authors have contributed equally to this work.
}

Received: 14 September 2020; Accepted: 21 October 2020; Published: 23 October 2020

check for updates

\begin{abstract}
In this study, we developed an aptamer-based fluorescent sensing platform for the detection of ochratoxin A (OTA) based on $\operatorname{Rec}_{\mathrm{f}}$ exonuclease-assisted signal amplification and interaction between graphene oxide (GO) and the OTA aptamer (OTA-apt). After optimizing the experimental conditions, the present aptamer-based sensing system can exhibit excellent fluorescent response in the OTA assay, with a limit of detection of $0.07 \mathrm{ng} / \mathrm{mL}$. In addition to signal amplification, this strategy is also highly specific for other interfering toxins. Furthermore, this aptasensor can be reliably used for assessing red wine samples spiked with different OTA concentrations $(2.4,6$ and $20 \mathrm{ng} / \mathrm{mL}$ ). The proposed assay plays an important role in the field of food safety and can be transformed for detecting other toxins by replacing the sequence that recognizes the aptamer.
\end{abstract}

Keywords: fluorescence; ochratoxin $\mathrm{A} ; \operatorname{Rec}_{\mathrm{f}}$ exonuclease; graphene oxide; signal amplification

Key Contribution: A novel fluorescence aptasensor for ochratoxin A determination with high sensitivity based on $\operatorname{Rec}_{\mathrm{f}}$ exonuclease-assisted signal amplification is reported.

\section{Introduction}

Ochratoxin A (OTA), a common mycotoxin, is a toxic secondary metabolite in fungi mainly produced by Aspergillus ochraceus, Aspergillus carbonarius, and Penicillium verrucosum [1]. Foodstuffs such as grains, coffee, cocoa, nuts, spices, wine, meat products, and dried fruits, are vulnerable to OTA contamination [2,3]. Toxicological studies have shown that OTA adversely affects humans as it may cause hepatotoxicity, nephrotoxicity, immunotoxicity, carcinogenicity, and teratogenicity [4]. In addition, excessive OTA in the human body can passively affect certain important biochemical processes; for example, it may increase lipid peroxidation, damage saccharide and calcium metabolism, and destroy mitochondrial function $[5,6]$. Removal of OTA at high temperature is challenging, and it has a half-life up to 35.5 days, which leads to its accumulation in the human body [7]. Owing to its potential threat to human health, OTA has been considered as a human carcinogen (Group 2B) by the International Agency for Research on Cancer (IARC), and the European Commission has stipulated that the maximum content of OTA in raw grains and soluble coffee is $5 \mu \mathrm{g} / \mathrm{kg}$ and $10 \mu \mathrm{g} / \mathrm{kg}$, respectively $[1,8]$. To eliminate the possible risk of OTA accumulation, efficient and sensitive assays for OTA quantitation should be urgently developed.

Traditionally, several analytical methods, including mass spectrometry (MS) [9], gas chromatography (GC) [10], thin-layer chromatography (TLC) [11], and high-performance liquid chromatography (HPLC) [12] have been used for OTA determination. Although these conventional methods exhibit low detection limits and high selectivity, the disadvantages are obvious, such as the 
requirement of multiple sample pretreatment, personnel training, and time-consuming operation. Recently, immunoassays, such as the enzyme-linked immunosorbent assay (ELISA), were developed as an alternative method for OTA analysis, which possesses the advantages of simplicity and sensitivity $[13,14]$. Nevertheless, ELISA involves complicated washing steps and the preparation of expensive antibodies. In addition, antibodies are susceptible to environmental conditions such as $\mathrm{pH}$, ionic strength, and temperature, which significantly restrict the range of application. Thus, high-efficiency and low-cost methods should be developed for detecting OTA.

Aptamers are short oligonucleotides or peptide molecules, screened using an in vitro selection process called systematic evolution of ligands by exponential enrichment (SELEX) [15-20]. They can form unique secondary structures, which can specifically bind to their target molecules such as small molecules, proteins, amino acids, cells, and tissues with high affinity [21-23]. Compared to antibodies, aptamers exhibit the following advantages. First, they can be easily chemically modified because of their small molecular weight. Second, highly stable aptamers with prominent target diversity can be easily synthesized at low cost. Owing to these outstanding merits, several aptamer-based methods for OTA determination have been developed, such as electrochemistry- [24,25], fluorescence- [26,27], and colorimetry-based assays $[28,29]$. The first OTA aptamer synthesized by Cruz-Aguado for OTA detection was reported in 2008 and this aptamer has been widely used in the construction of many biosensors [30]. For example, Kuang et al. established an aptamer-based electrochemical strategy for detecting OTA [31]. Despite showing higher sensitivity, its performance was limited by long analysis time and the use of tedious electrode preparation steps. Lee et al. proposed a colorimetric aptamer sensor for OTA determination based on the formation of G-quadruplex DNAzymes [29]. However, this strategy has relatively low sensitivity. Analysis based on fluorescence has attracted widespread attention because of facile operation process, high sensitivity, and low production cost. Nonetheless, the aptamer and targeted molecule binding ratio is 1:1 in these methods, which limits signal amplification. Hence, fluorescence-based methods that can result in signal amplification are urgently required.

As a derivative of graphene, graphene oxide (GO) has gained considerable attention due to its special optical, electronic, and thermal properties, and aqueous dispersibility [32]. GO can adsorb single-stranded DNA (ssDNA) via hydrophobic interactions, hydrogen bonding, and $\pi$-stacking interactions, whereas rigid double-stranded DNA (dsDNA) or well-folded DNA cannot be adsorbed on the surface of GO $[33,34]$. Based on these characteristics, GO coupled with DNA-based detection strategies has been successfully utilized for the detection of several targets $[35,36]$.

In this study, we propose an aptamer-based fluorescent strategy that involves $\mathrm{Rec}_{\mathrm{f}}$ exonuclease $\left(\operatorname{Rec}_{\mathrm{f}}\right.$ exo)-triggered signal amplification on a GO platform. The high affinity of OTA aptamer (OTA-apt) against OTA can hinder the adsorption on GO and subsequently initiate digestion with $\operatorname{Rec}_{\mathrm{f}} \mathrm{exO}_{\mathrm{O}}$ The amplified fluorescent signal is obtained by coupling RecJ $\mathrm{f}_{\mathrm{f}}$ exo with the catalytic recycling of OTA. The proposed sensing platform is highly sensitive and selective for OTA and can be successfully used for OTA analysis in real samples.

\section{Results and Discussion}

\subsection{Principle of the OTA Assay}

In this study, a sensitive and highly efficient aptamer-based fluorescent signal amplification strategy for OTA detection based on GO and $\operatorname{Rec}_{\mathrm{f}}$ exo was proposed, the mechanism of which is illustrated in Figure 1a. OTA-apt shows remarkable fluorescence owing to the presence of carboxyfluorescein (FAM) at its $5^{\prime}$ end. In the absence of OTA, FAM-labeled OTA-apt can be adsorbed on GO surface via $\pi$-stacking interactions between nucleobases and the GO surface, and the electrostatic driving force. The conjugation of OTA-apt to GO can effectively prevent the OTA-apt from undergoing $\operatorname{Rec}_{\mathrm{f}}$ exo cleavage. Consequently, a quenching fluorescence signal was observed. On the contrary, OTA can specifically bind to its target OTA-apt, inducing changes in the conformation of OTA-apt from ssDNA 
to antiparallel G-quadruplex, which cannot be adsorbed on the GO surface [37]. The free OTA-apt can be hydrolyzed by $\operatorname{RecJ}_{\mathrm{f}}$ exo based on its ability to remove monodeoxynucleotides from ssDNA in the $5^{\prime}-3^{\prime}$ direction, thereby releasing the FAM fluorophore and OTA [38]. As a result, a strong fluorescence signal was obtained. The freed OTA can bind with another OTA-apt to initiate a new cycle of cleavage reaction. Using this $\operatorname{Rec}_{\mathrm{f}}$ exo-assisted signal amplification strategy, an increasing amount of OTA-apt can be digested with a low amount of OTA, which significantly increases the detection sensitivity. Thus, on the basis of the changes in fluorescence signal, quantitative and sensitive analysis of OTA can be realized.

(a)

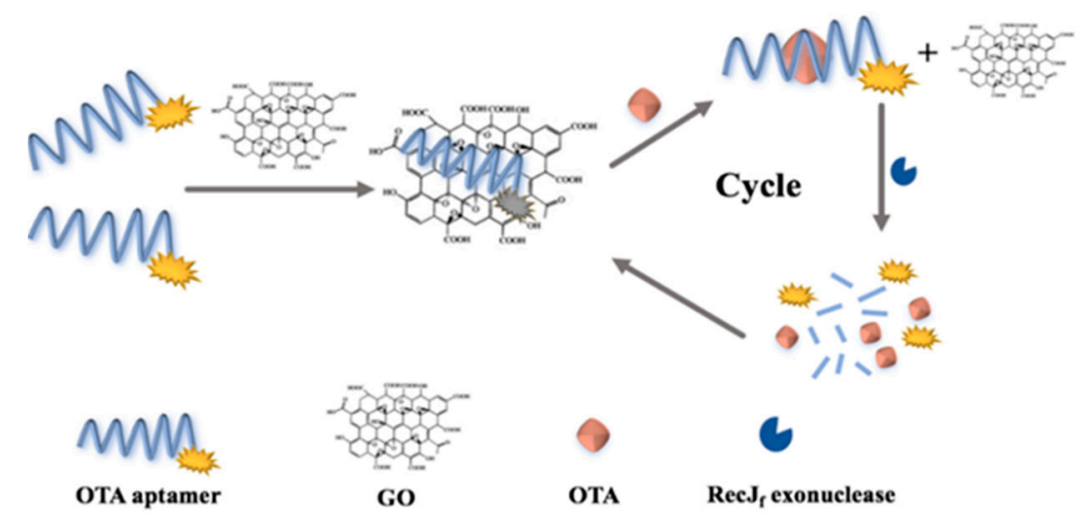

(b)

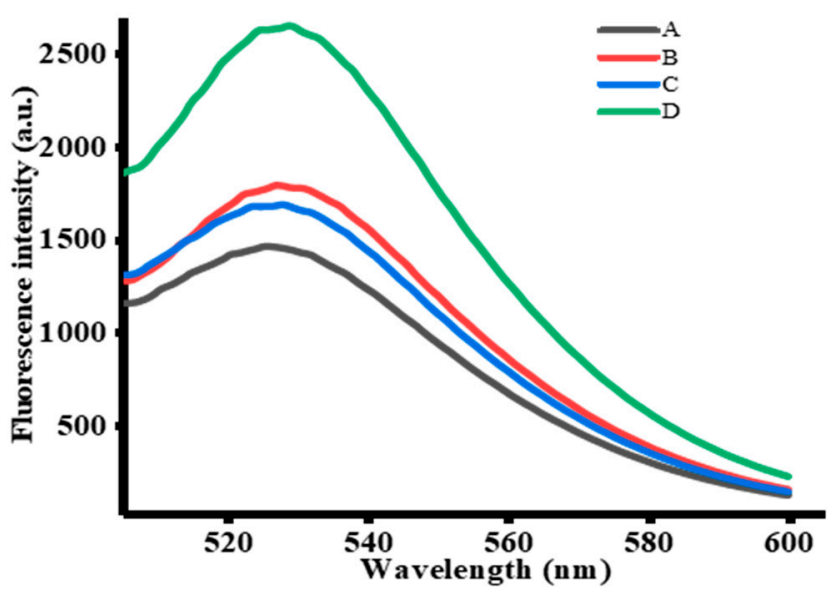

Figure 1. (a) Schematic illustration of $\operatorname{Rec}_{\mathrm{f}}$ exo-assisted signal amplification strategy for ochratoxin A (OTA) detection. (b) Fluorescence emission spectra of FAM-labeled OTA-apt under different cases $(n=3)$. (A) OTA-apt + graphene oxide (GO), (B) OTA + OTA-apt + GO, (C) OTA-apt + GO + RecJ $\mathrm{f}_{\mathrm{f}}$ exo, (D) OTA + OTA-apt + GO + RecJ $\mathrm{f}_{\mathrm{f}}$ exo. The concentrations of OTA, OTA-apt, GO, and RecJ $\mathrm{f}_{\mathrm{f}}$ exo were $400 \mathrm{ng} / \mathrm{mL}, 300 \mathrm{nM}, 10 \mu \mathrm{g} / \mathrm{mL}$, and $0.06 \mathrm{U} / \mu \mathrm{L}$, respectively.

\subsection{Feasibility of the Designed Strategy}

To confirm the feasibility of this aptasensor, the fluorescence emission spectrum of FAM-labeled OTA-apt under different circumstances was studied. Firstly, we investigated the variation in fluorescence intensity without $R e J_{f}$ exo. As can be seen from Figure 1b, a lower fluorescence signal was measured (curve A) with the introduction of OTA-apt and GO, indicating that the fluorescence of FAM was quenched by GO. Previous reports have shown that graphene can be used as a good quencher of organic dyes based on fluorescence resonance energy transfer effect (FRET) from dyes to graphene. Conversely, as depicted in curve B, a prominent fluorescence enhancement was observed upon addition of OTA. This phenomenon indicated that the high affinity of OTA-apt against OTA can induce the formation of OTA/OTA-apt complex, which is a steady antiparallel G-quadruplex structure that can be desorbed from the GO surface and can hinder the FRET from FAM to GO. We further 
investigated the signal amplification strategy using $\operatorname{Rec}_{\mathrm{f}}$ exo. In this condition, only a slight increase in background fluorescence (curve $\mathrm{C}$ ) was monitored compared to curve A without OTA. Nevertheless, in the presence of OTA and $\operatorname{Rec}_{\mathrm{f}}$ exo, the fluorescence intensity obtained from curve D was stronger than that in the absence of RecJ $J_{f}$ exo (curve B), which was attributed to RecJ $J_{f}$ exo-catalyzed hydrolysis of OTA-apt and the release of OTA and the fluorophore. The obtained OTA can combine with another OTA-apt to initiate a new cycle, and, as this proceeds, the amount of fluorophores generated increases. Thus, a small amount of OTA can lead to the release of a considerable amount of fluorophores, dramatically amplifying the fluorescence signal. Above all, these intriguing results suggest that this signal-amplifying aptasensor can be successfully applied to OTA assay.

\subsection{Optimization of Experimental Conditions}

To acquire a desirable sensing performance, several pivotal parameters, such as the concentration of OTA-apt, GO, and RecJ $\mathrm{f}_{\mathrm{f}}$ exo, and amplification time, which may affect fluorescent response, were optimized. As depicted in Figure 2A, with the concentration of OTA-apt gradually increased from 200 to $300 \mathrm{~nm}$, the enhanced fluorescence signal can be observed. However, the fluorescence intensity was gradually quenched after $300 \mathrm{nM}$. We speculated that excessive OTA-apt cannot be absorbed on the GO surface, leading to an increase in background fluorescence $\left(\mathrm{F}_{0}\right)$. Therefore, $300 \mathrm{nM}$ OTA-apt was selected for OTA analysis in subsequent work. The concentration of GO, which is closely related to its ability to adsorb OTA-apt, was further optimized and the results are shown in Figure 2B. The fluorescence response to OTA increased with the concentration of GO up to $10 \mu \mathrm{g} / \mathrm{mL}$ and then decreased drastically. This is mainly due the fact that excess GO may adsorb OTA/OTA-apt complex. Thus, $10 \mu \mathrm{g} / \mathrm{mL}$ of GO was used throughout the experiment. $\mathrm{Rec}_{\mathrm{f}}$ exo, which is a single-strand-specific exonuclease, plays a crucial role in this signal amplification strategy and its concentration was also optimized. Figure 2C shows that the ratio of fluorescence intensity increased significantly with the concentration of $\operatorname{Rec}_{\mathrm{f}}$ exo and approached a maximum at $0.06 \mathrm{U} / \mu \mathrm{L}$, indicating that the digestion process had reached saturation. Finally, the effect of $\operatorname{Rec}_{\mathrm{f}}$ exo amplification time on fluorescence signal was researched. As shown in Figure 2D, the relative fluorescence intensity peaked after $90 \mathrm{~min}$, indicating the completion of OTA-apt hydrolysis by $\operatorname{Rec}_{\mathrm{f}}$ exo. 

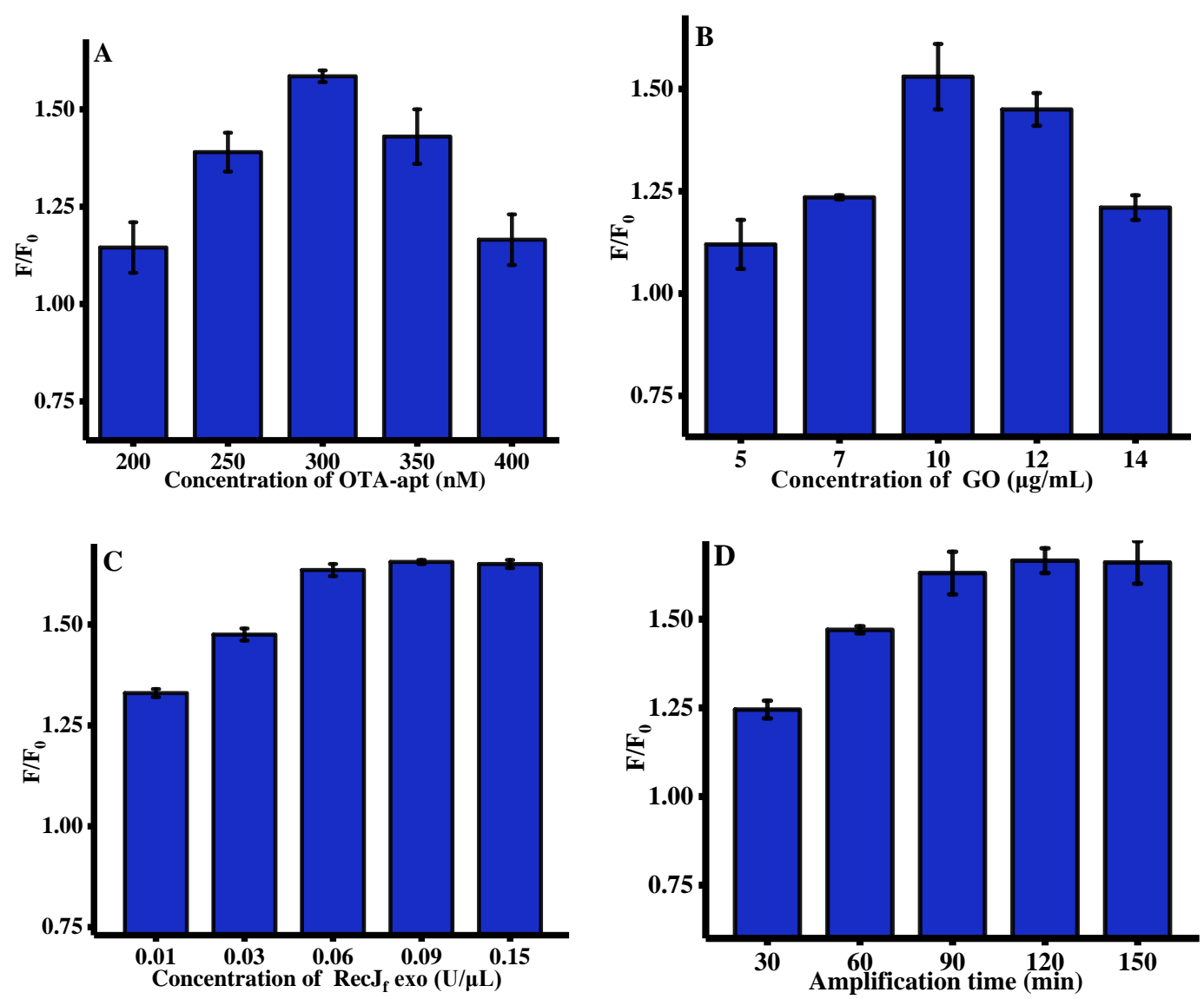

Figure 2. Optimization of experimental conditions for OTA assay $(n=3)$. (A) Concentration of OTA-apt, $(\mathrm{GO})=10 \mu \mathrm{g} / \mathrm{mL}, \operatorname{Rec}_{\mathrm{f}}$ exo $=0.2 \mathrm{U} / \mu \mathrm{L},($ Amplification time) $=90 \mathrm{~min}$, (OTA reaction time) $=15 \mathrm{~min} ;(\mathbf{B})$ concentration of $\mathrm{GO},(\mathrm{OTA}-\mathrm{apt})=300 \mathrm{nM},\left(\operatorname{Rec}_{\mathrm{f}} \mathrm{exo}\right)=0.2 \mathrm{U} / \mu \mathrm{L},($ Amplification time $)$ $=90 \mathrm{~min},(\mathrm{OTA}$ reaction time $)=15 \mathrm{~min} ;(\mathrm{C})$ concentration of $\operatorname{Rec}_{\mathrm{f}}$ exo, $(\mathrm{OTA}-\mathrm{apt})=300 \mathrm{nM},(\mathrm{GO})$ $=10 \mu \mathrm{g} / \mathrm{mL},($ Amplification time $)=90 \mathrm{~min},(\mathrm{OTA}$ reaction time $)=15 \mathrm{~min}$; (D) amplification time, $(\mathrm{OTA}-\mathrm{apt})=300 \mathrm{nM},(\mathrm{GO})=10 \mu \mathrm{g} / \mathrm{mL},\left(\operatorname{Rec}_{\mathrm{f}}\right.$ exo $)=0.06 \mathrm{U} / \mu \mathrm{L},(\mathrm{OTA}$ reaction time $)=15 \mathrm{~min} . \mathrm{F}_{0}$ and $\mathrm{F}$ were the fluorescence intensities in the absence and presence of OTA. (OTA) $=500 \mathrm{ng} / \mathrm{mL}$, (excitation wavelength) $=490 \mathrm{~nm}$, (emission wavelength) $=525 \mathrm{~nm}$. Error bars represented the standard deviation of three experiments.

\subsection{Quantitative Determination of OTA}

Under the optimized experimental conditions, the sensing performance of signal amplification strategy was assessed by adding various concentrations of OTA (i.e., $0-400 \mathrm{ng} / \mathrm{mL}$ ) into the reaction system. Figure 3A shows the fluorescence emission spectra of FAM-labeled OTA-apt with different concentrations of OTA. It is apparent that the fluorescence emission intensity at $525 \mathrm{~nm}$ proportionally raised with OTA concentrations and plateaued at $400 \mathrm{ng} / \mathrm{mL}$. This demonstrated that the antiparallel G-quadruplex structure formed by the specific binding of OTA with OTA-apt cannot be adsorbed on GO surface, resulting in a high fluorescence. The inset of Figure 3B shows the calibration curve for quantitative detection of OTA. A good linear relationship between fluorescence intensity and OTA concentration was observed with the dynamic range from 0.2 to $32 \mathrm{ng} / \mathrm{mL}$. Using the origin software calculation, the linear regression equation obtained was $\mathrm{F}=10.001 \mathrm{C}+1709.43$ with a correlation coefficient of 0.999 , where $\mathrm{C}$ was the concentration of OTA $(\mathrm{ng} / \mathrm{mL})$ and F represented peak intensity. The limit of detection (LOD) was accessed to be $0.07 \mathrm{ng} / \mathrm{mL}$ in accordance with the $3 \sigma$ rule. In comparison with previous sensing platforms listed in Table 1 , the detection limit of our strategy is superior than that of colorimetric method, carbon nanohorns-based fluorescence method, SYBR gold-based fluorescence method and copper nanoparticles-based fluorescence method. 
Despite many advantages in colorimetric assay, such as wider linear range, they are still affected by comparatively lower sensitivity and anti-interference ability. Electrochemical methods exhibit excellent detection performance, but the process of sensor fabrication is complicated, and the analysis process is time-consuming $[39,40]$. What is more, compared with the other fluorescent method shown in Table 1 , the present work we proposed exhibits higher sensitivity, stability and reproducibility [3,41,42]. Hence, we concluded that this sensing strategy can be used for OTA determination with high sensitivity. At the same time, this fluorescence-based aptasensor can be further utilized for the other toxins analysis by replacing the specific sequence of the aptamer [43].
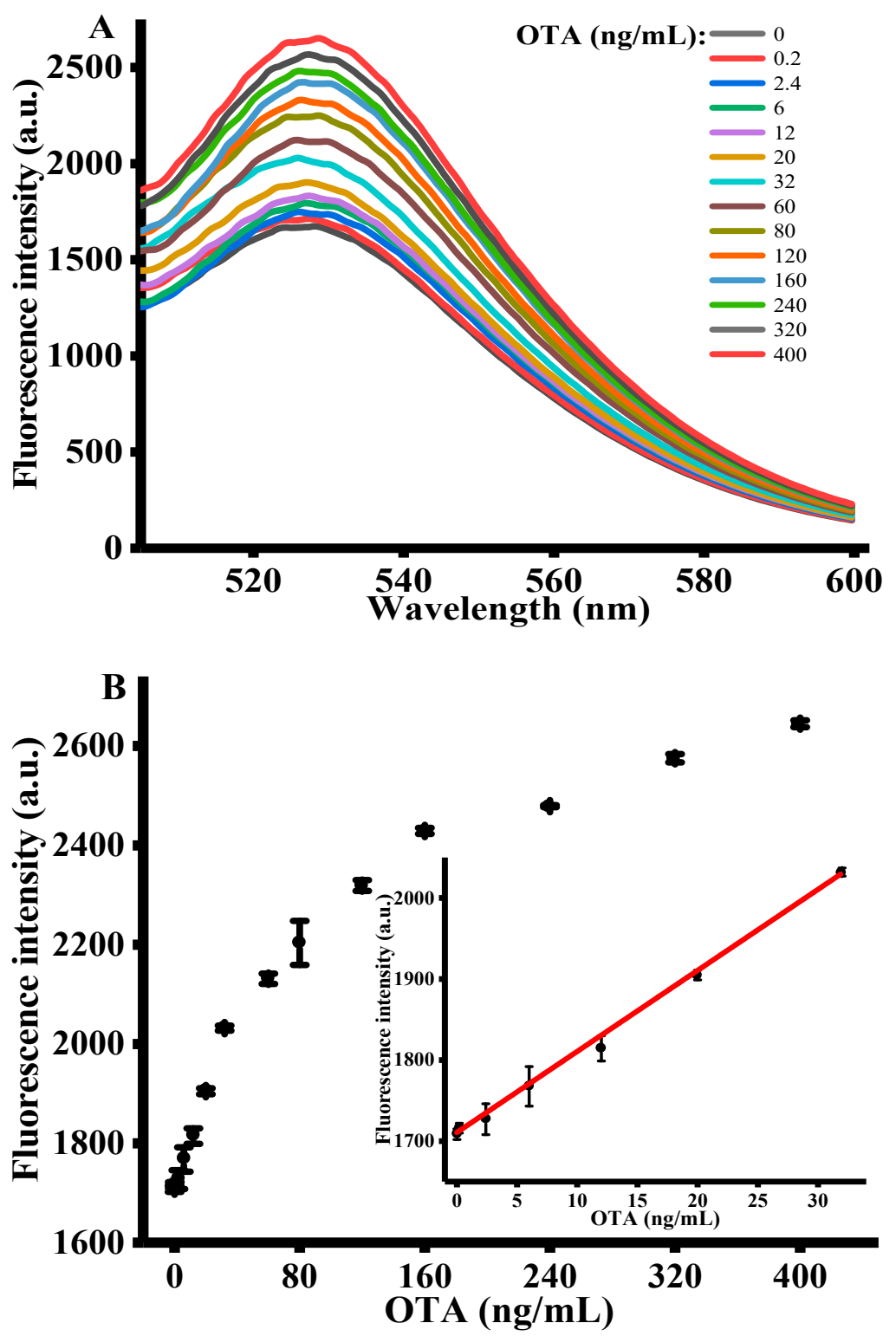

Figure 3. (A) Fluorescent emission spectra with different concentrations of OTA $(n=3)$. (B) The relationship between the fluorescence intensity and OTA concentration. (OTA-apt) $=300 \mathrm{nM},(\mathrm{GO})$ $=10 \mu \mathrm{g} / \mathrm{mL},($ OTA reaction time $)=15 \mathrm{~min},\left(\operatorname{Rec}_{\mathrm{f}} \mathrm{exo}\right)=0.06 \mathrm{U} / \mu \mathrm{L},($ Amplification time $)=90 \mathrm{~min}$, (excitation wavelength) $=490 \mathrm{~nm}$, (emission wavelength $)=525 \mathrm{~nm}$. Error bars were obtained from three replicated measurements. 
Table 1. Comparison with different reported methods for OTA detection.

\begin{tabular}{ccccc}
\hline Method & Material & LOD $(\mathbf{n g} / \mathbf{m L})$ & Dynamic Range $(\mathbf{n g} / \mathbf{m L})$ & Reference \\
\hline Colorimetry & Gold nanorods & 44 & $4-80$ & {$[28]$} \\
Colorimetry & G-quadruplex DNAzymes & 0.4 & - & {$[29]$} \\
Electrochemistry & Magnetic nanoparticles & 0.01 & $0.01-5$ & {$[39]$} \\
Electrochemistry & Polythiophene-3-carboxylic acid & 0.125 & $0.125-2.5$ & {$[40]$} \\
Fluorescence & Carbon nanohorns & 1.6 & $4-400$ & {$[3]$} \\
Fluorescence & SYBR gold & 4.7 & $8-1000$ & {$[41]$} \\
Fluorescence & Copper nanoparticles & 5 & $0-100$ & {$[42]$} \\
Fluorescence & Graphene oxide & 0.07 & $0.2-32$ & This work \\
\hline
\end{tabular}

\subsection{Evaluation of Specificity}

The selectivity of this fluorescent aptasensor towards OTA was evaluated using OTB and aflatoxin $\mathrm{B}_{1}\left(\mathrm{AFB}_{1}\right)$ as controls [6]. As shown in Figure 4, only OTA, but not other toxins, such as OTB and $\mathrm{AFB}_{1}$, generated an intense fluorescence enhancement. This was primarily attributed to unique specificity of OTA-apt toward OTA [44]. These satisfactory results were indicative of the selectivity of this method and the broad prospects for its practical application in real samples.

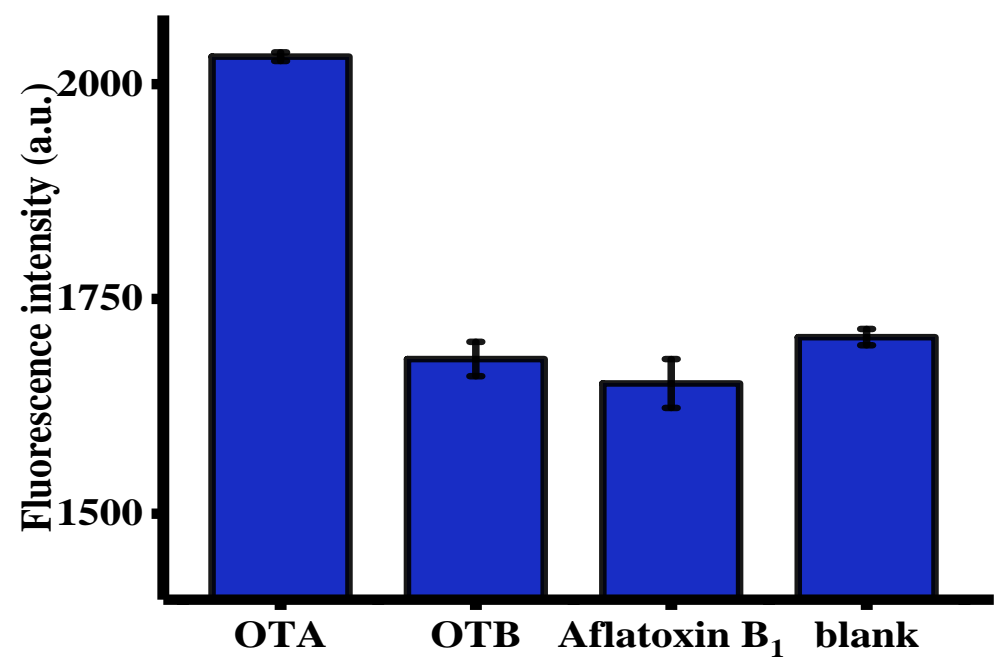

Figure 4. Selectivity of the signal amplification of the aptasensor toward OTA, OTB, and aflatoxin $B_{1}$ $\left(\mathrm{AFB}_{1}\right)(n=3)$. The concentration of OTA was $32 \mathrm{ng} / \mathrm{mL}$. The concentration of OTB and $\mathrm{AFB}_{1}$ were both of $100 \mathrm{ng} / \mathrm{mL}$. Error bars were obtained from three replicated measurements.

\subsection{OTA Assay in Red Wine Samples}

In order to verify the applicability and accuracy of this fluorescent aptasensor for the analysis of red wine samples, recovery experiments for OTA determination were performed in 20-fold diluted red wine samples [38]. The corresponding results are displayed in Table 2 . The fluorescence signal recovery was $93.8,97.3$, and $106.6 \%$ in the samples spiked with $2.4,6$, and $20 \mathrm{ng} / \mathrm{mL}$ of OTA, respectively, confirming the viability of this method for OTA assay in drink samples.

Table 2. Application of aptasensor for OTA detection in red wine.

\begin{tabular}{cccc}
\hline Sample & Added $(\mathbf{n g} / \mathbf{m L})$ & Found $(\mathbf{n g} / \mathbf{m L})$ & Recovery $(\%)$ \\
\hline 1 & 2.4 & $2.25 \pm 0.28$ & 93.8 \\
2 & 6 & $5.84 \pm 0.46$ & 97.3 \\
3 & 20 & $21.31 \pm 0.32$ & 106.6 \\
\hline
\end{tabular}




\section{Conclusions}

In general, a fluorescence-based aptasensor was designed for ultrasensitive determination of OTA, which relied on OTA-induced release of OTA-apt from the GO surface and RecJ $\mathrm{f}_{\mathrm{f}}$ exo-catalyzed cyclic signal amplification. We suggest that this signal amplification strategy exhibited several merits. First, this method showed high sensitivity, with an extremely low detection limit of $0.07 \mathrm{ng} / \mathrm{mL}$, due to $\operatorname{Rec}_{\mathrm{f}}$ exo-assisted target recycling amplification. In addition, studies on the effect of certain interfering mycotoxins on the detection platform have confirmed its excellent selectivity. In addition, this sensing strategy has been successfully applied for OTA assay in real samples with encouraging results. This signal amplified aptasensor can be modified for the detection of a wide range of targets by using their corresponding aptamers. Thus, this method may find an extensive application prospect in the fields of food hygiene and environmental science.

\section{Materials and Methods}

\subsection{Materials and Reagents}

Ochratoxin A (OTA) and ochratoxin B (OTB) were purchased from Pribolab Co., Ltd. (Qingdao, China). Aflatoxin $\mathrm{B}_{1}\left(\mathrm{AFB}_{1}\right)$ was obtained from Yuanye Co., Ltd. (Shanghai, China). Graphene oxide (GO) was bought from XFNANO Materials Tech Co., Ltd. (Nanjing, China). RecJ exonuclease $\left(\operatorname{Rec}_{\mathrm{f}}\right.$ exo) and $10 \times$ NEBuffer $2(10 \mathrm{mM}$ Tris- $\mathrm{HCl}, 50 \mathrm{mM} \mathrm{NaCl}, 10 \mathrm{mM} \mathrm{MgCl} 2,1 \mathrm{mM}$ DTT, pH 7.9) were ordered from Takara Biotechnology Co., Ltd. (Dalian, China). The FAM-labeled DNA probe was synthesized by Sangon Biotechnology Co., Ltd. (Shanghai, China). The DNA sequence was dissolved in TE buffer and stored at $-20^{\circ} \mathrm{C}$ for further use. The sequence of DNA probe was listed as follows: 5'-FAM-GATCGGGTGTGGGTGG CGTAAAGGGAGCATCGGACA-3'. Ultrapure water (18.2 $\mathrm{M} \Omega . \mathrm{cm}$ ) processed with a Milli-Q water purification system (Millipore Corp, Bedford, MA, USA) was used in the whole experiment.

\subsection{Apparatus}

Fluorescent emission spectra and fluorescence intensities were measured using an F-2700 fluorescence spectrophotometer (Hitachi, Japan). The excitation wavelength was set at $490 \mathrm{~nm}$ at room temperature and emission spectra were recorded in the wavelength of 505-600 nm with slit widths of emission and excitation both set at $5 \mathrm{~nm}$.

\subsection{Optimization of Reaction Conditions}

To obtain the best experimental performance, several reaction parameters were first optimized, including the concentrations of OTA aptamer (OTA-apt), GO, and Rec $\mathrm{f}_{\mathrm{f}}$ exo, and amplification time. The OTA-apt concentration ranged from $200 \mathrm{nM}$ to $400 \mathrm{nM}$. The GO concentration used was $5-14 \mu \mathrm{g} / \mathrm{mL}$. The concentration of $\operatorname{Rec}_{\mathrm{f}}$ exo used was $0.0-0.15 \mathrm{U} / \mu \mathrm{L}$. The amplification time was 30-150 min.

\subsection{Fluorescent Detection of OTA}

OTA was detected quantitatively as described below. First, a series of OTA concentrations $(0-400 \mathrm{ng} / \mathrm{mL})$ and $300 \mathrm{nM}$ OTA-apt with the FAM fluorophore were added into the $1 \times$ NEBuffer 2 (10 mM Tris- $\mathrm{HCl}, 50 \mathrm{mM} \mathrm{NaCl}, 10 \mathrm{mM} \mathrm{MgCl}, 1 \mathrm{mM}$ DTT, pH 7.9). The mixture was incubated for $15 \mathrm{~min}$ at $25^{\circ} \mathrm{C}$. Subsequently, $10 \mu \mathrm{g} / \mathrm{mL} \mathrm{GO}$ was added and allowed to incubate at $25^{\circ} \mathrm{C}$ for $15 \mathrm{~min}$. Afterwards, $0.06 \mathrm{U} / \mu \mathrm{L} \mathrm{RecJ_{ \textrm {f } }}$ exo was added for the digestion reaction in a final volume of $100 \mu \mathrm{L}$. After incubation for $90 \mathrm{~min}$ at $37^{\circ} \mathrm{C}$, the fluorescence intensity was recorded at room temperature using a F-2700 fluorescence spectrophotometer. 


\subsection{OTA Assay in Red Wine Samples}

To verify the feasibility and reliability of the proposed protocol for OTA analysis in practical applications, red wine, which was purchased from a local supermarket, was utilized as the actual sample. Prior to the recovery experiment, the wine sample was filtered to remove the sediment and diluted with buffer solution. Then, 2.4, 6, and $12 \mathrm{ng} / \mathrm{mL}$ OTA were spiked into 20-fold diluted red wine samples. The samples of different OTA concentrations were measured three times, respectively. The subsequent reaction process and fluorescent measurements were the same as that described above.

Author Contributions: Conceptualization, C.M.; software, D.X.; formal analysis, H.Z. and Y.Y.; investigation, H.Z. and Y.Y; writing-original draft preparation, H.Z.; writing-review and editing, D.X. and C.M.; supervision, C.M.; project administration, C.M.; funding acquisition, D.X. All authors have read and agreed to the published version of the manuscript.

Funding: This research was funded by National Natural Science Foundation of China (No. 21205142), Natural Science Foundation of Hunan Province of China (No. 2019JJ40370) and the Research Innovation Program for Graduates of Central South University (2018zzts384, 2019zzts453).

Conflicts of Interest: The authors declare no conflict of interest.

\section{References}

1. Van der Merwe, K.J.; Steyn, P.S.; Fourie, L.; Scott, D.B.; Theron, J.J. Ochratoxin A, a toxic metabolite produced by Aspergillus ochraceus Wilh. Nature 1965, 205, 1112-1113. [CrossRef] [PubMed]

2. Covarelli, L.; Beccari, G.; Marini, A.; Tosi, L. A review on the occurrence and control of ochratoxigenic fungal species and ochratoxin A in dehydrated grapes, non-fortified dessert wines and dried vine fruit in the Mediterranean area. Food Control. 2012, 26, 347-356. [CrossRef]

3. Wu, H.; Liu, R.J.; Kang, X.J.; Liang, C.Y.; Lv, L.; Guo, Z.G. Fluorometric aptamer assay for ochratoxin A based on the use of single walled carbon nanohorns and exonuclease III-aided amplification. Mirochim. Acta 2017, 185, 27. [CrossRef] [PubMed]

4. Pfohl-Leszkowicz, A.; Manderville, R.A. Ochratoxin A: An overview on toxicity and carcinogenicity in animals and humans. Mol. Nutr. Food Res. 2007, 51, 61-99. [CrossRef] [PubMed]

5. Costa, J.G.; Saraiva, N.; Guerreiro, P.S.; Louro, H.; Silva, M.J.; Miranda, J.P.; Castro, M.; Batinic-Haberle, I.; Fernandes, A.S.; Oliveira, N.G. Ochratoxin A-induced cytotoxicity, genotoxicity and reactive oxygen species in kidney cells: An integrative approach of complementary endpoints. Food Chem. Toxicol. 2016, 87, 65-76. [CrossRef]

6. Wu, K.F.; Ma, C.B.; Zhao, H.; Chen, M.J.; Deng, Z.Y. Sensitive aptamer-based fluorescene assay for ochratoxin A based on RNase H signal amplification. Food Chem. 2019, 277, 273-278. [CrossRef] [PubMed]

7. Studer-Rohr, I.; Schlatter, J.; Dietrich, D.R. Kinetic parameters and intraindividual fluctuations of ochratoxin A plasma levels in humans. Arch. Toxicol. 2000, 74, 499-510. [CrossRef]

8. Wei, Y.; Zhang, J.; Wang, X.; Duan, Y.X. Amplified fluorescent aptasensor through catalytic recycling for highly sensitive detection of ochratoxin A. Biosens. Bioelectron. 2015, 65, 16-22. [CrossRef] [PubMed]

9. Reinsch, M.; Töpfer, A.; Lehmann, A.; Nehls, I.; Panne, U. Determination of ochratoxin A in beer by LC-MS/MS ion trap detection. Food Chem. 2007, 100, 312-317. [CrossRef]

10. Olsson, J.; Börjesson, T.; Lundstedt, T.; Schnürer, J. Detection and quantification of ochratoxin A and deoxynivalenol in barley grains by GC-MS and electronic nose. Int. J. Food Microbiol. 2002, 72, 203-214. [CrossRef]

11. Pittet, A.; Royer, D. Rapid, low cost thin-layer chromatographic screening method for the detection of ochratoxin A in green coffee at a control level of $10 \mathrm{microg} / \mathrm{kg}$. J. Agric. Food Chem. 2002, 50, $243-247$. [CrossRef] [PubMed]

12. Tessini, C.; Mardones, C.; von Baer, D.; Vega, M.; Herlitz, E.; Saelzer, R.; Silva, J.; Torres, O. Alternatives for sample pre-treatment and HPLC determination of Ochratoxin A in red wine using fluorescence detection. Anal. Chim. Acta 2010, 660, 119-126. [CrossRef] [PubMed]

13. Yu, F.Y.; Chi, T.F.; Liu, B.H.; Su, C.C. Development of a sensitive enzyme-linked immunosorbent assay for the determination of ochratoxin A. J. Agric. Food Chem. 2005, 53, 6947-6953. [CrossRef] 
14. Liu, B.H.; Tsao, Z.J.; Wang, J.J.; Yu, F.Y. Development of a monoclonal antibody against ochratoxin A and its application in enzyme-linked immunosorbent assay and gold nanoparticle immunochromatographic strip. Anal. Chem. 2008, 80, 7029-7035. [CrossRef] [PubMed]

15. Tuerk, C.; Gold, L. Systematic evolution of ligands by exponential enrichment: RNA ligands to bacteriophage T4 DNA polymerase. Science 1990, 249, 505-510. [CrossRef]

16. Ellington, A.D.; Szostak, J.W. In vitro selection of RNA molecules that bind specific ligands. Nature 1990, 346, 818-822. [CrossRef]

17. Zhou, J.; Battig, M.R.; Wang, Y. Aptamer-based molecular recognition for biosensor development. Anal. Bioanal. Chem. 2010, 398, 2471-2480. [CrossRef]

18. Dai, S.; Wu, S.; Duan, N.; Wang, Z. A luminescence resonance energy transfer based aptasensor for the mycotoxin Ochratoxin A using upconversion nanoparticles and gold nanorods. Microchim. Acta 2016, 183, 1909-1916. [CrossRef]

19. Huo, Y.; Qi, L.; Lv, X.J.; Lai, T.; Zhang, J.; Zhang, Z.Q. A sensitive aptasensor for colorimetric detection of adenosine triphosphate based on the protective effect of ATP-aptamer complexes on un- modified gold nanoparticles. Biosens. Bioelectron. 2016, 78, 315-320. [CrossRef] [PubMed]

20. Lv, L.; Li, D.H.; Cui, C.B.; Zhao, Y.Y.; Guo, Z.J. Nuclease-aided target recycling signal amplification strategy for ochratoxin A monitoring. Biosens. Bioelectron. 2017, 87, 136-141. [CrossRef]

21. Liu, H.S.; Ma, C.B.; Ning, F.; Chen, H.C.; He, H.L.; Wang, K.M.; Wang, J. A facile label-free G-quadruplex based fluorescent aptasensor method for rapid detection of ATP. Spectrochim. Acta A Mol. Biomol. Spectrosc. 2017, 175, 164-167. [CrossRef] [PubMed]

22. Chen, M.J.; Tang, Z.W.; Ma, C.B.; Yan, Y. A fluorometric aptamer based assay for prostate specific antigen based on enzyme-assisted target recycling. Sens. Actuators B Chem. 2020, 302, 127178. [CrossRef]

23. Xia, X.; Wang, Y.; Yang, H.; Dong, Y.; Zhang, K.; Lu, Y.; Deng, R.; He, Q. Enzyme-free amplified and ultrafast detection of aflatoxin B-1 using dual-terminal proximity aptamer probes. Food Chem. 2019, 283, 32-38. [CrossRef]

24. Wu, J.J.; Chu, H.Q.; Mei, Z.L.; Deng, Y.; Xue, F.; Zheng, L.; Chen, W. Ultrasensitive one-step rapid detection of ochratoxin A by the folding-based electrochemical aptasensor. Anal. Chim. Acta 2012, 753, 27-31. [CrossRef]

25. Sun, A.L.; Zhang, Y.F.; Sun, G.P.; Wang, X.N.; Tang, D. Homogeneous electrochemical detection of ochratoxin $\mathrm{A}$ in foodstuff using aptamer-graphene oxide nanosheets and DNase I-based target recycling reaction. Biosens. Bioelectron. 2017, 89, 659-665. [CrossRef] [PubMed]

26. Zhao, H.; Xiang, X.Y.; Chen, M.J.; Ma, C.B. Aptamer-Based Fluorometric Ochratoxin A Assay Based on Photoinduced Electron Transfer. Toxins 2019, 11, 65. [CrossRef] [PubMed]

27. Wu, K.F.; Ma, C.B.; Zhao, H.; He, H.L.; Chen, H.C. Label-Free G-Quadruplex Aptamer Fluorescence Assay for Ochratoxin A Using a Thioflavin T Probe. Toxins 2018, 10, 198. [CrossRef]

28. Yu, X.H.; Lin, Y.H.; Wang, X.S.; Xu, L.G.; Wang, Z.W.; Fu, F.F. Exonuclease-assisted multicolor aptasensor for visual detection of ochratoxin A based on G-quadruplex-hemin DNAzyme-mediated etching of gold nanorod. Microchim. Acta 2018, 185, 259. [CrossRef]

29. Lee, J.; Jeon, C.H.; Ahn, S.J.; Ha, T.H. Highly stable colorimetric aptamer sensors for detection of ochratoxin A through optimizing the sequence with the covalent conjugation of hemin. Analyst 2014, 139, 1622-1627. [CrossRef]

30. Cruz-Aguado, J.A.; Penner, G. Determination of ochratoxin a with a DNA aptamer. J. Agric. Food Chem. 2008, 56, 10456-10461. [CrossRef]

31. Kuang, H.; Chen, W.; Xu, D.H.; Xu, L.G.; Zhu, Y.Y.; Liu, L.Q.; Chu, H.Q.; Peng, C.F.; Xu, C.L.; Zhu, S.F. Fabricated aptamer-based electrochemical "signal-off" sensor of ochratoxin A. Biosens. Bioelectron. 2010, 26, 710-716. [CrossRef]

32. Swathi, R.S.; Sebastian, K.L. Long range resonance energy transfer from a dye molecule to graphene has (distance)(-4) dependence. J. Chem. Phys. 2009, 130, 086101. [CrossRef] [PubMed]

33. Toda, K.; Furue, R.; Hayami, S. Recent progress in applications of graphene oxide for gas sensing: A review. Anal. Chim. Acta 2015, 878, 43-53. [CrossRef]

34. Lee, J.; Kim, Y.K.; Min, D.H. A new assay for endonuclease/methyltransferase activities based on graphene oxide. Anal. Chem. 2011, 83, 8906-8912. [CrossRef] [PubMed] 
35. Chen, J.; Ge, J.; Zhang, L.; Li, Z.H.; Li, J.J.; Sun, Y.J.; Qu, L.B. Reduced graphene oxide nanosheets functionalized with poly (styrene sulfonate) as a peroxidase mimetic in a colorimetric assay for ascorbic acid. Microchim. Acta 2016, 183, 1847-1853. [CrossRef]

36. Chen, M.J.; Li, W.K.; Ma, C.B.; Wu, K.F.; He, H.L.; Wang, K.M. Fluorometric determination of the activity of uracil-DNA glycosylase by using graphene oxide and exonuclease I assisted signal amplification. Microchim. Acta 2019, 186, 110. [CrossRef] [PubMed]

37. Sheng, L.F.; Ren, J.T.; Miao, Y.Q.; Wang, J.H.; Wang, E.K. PVP-coated graphene oxide for selective determination of ochratoxin A via quenching fluorescence of free aptamer. Biosens. Bioelectron. 2011, 26, 3494-3499. [CrossRef]

38. Yi, H.Y.; Xu, W.J.; Yuan, Y.L.; Wu, Y.M.; Chai, Y.Q.; Yuan, R. A sensitive electrochemical aptasensor for thrombin detection based on exonuclease-catalyzed target recycling and enzyme-catalysis. Biosens. Bioelectron. 2013, 47, 368-372. [CrossRef]

39. Zamfir, L.G.; Geana, I.; Bourigua, S.; Rotariu, L.; Bala, C.; Errachid, A.; Jaffrezic-Renault, N. Highly sensitive label-free immunosensor for ochratoxin A based on functionalized magnetic nanoparticles and EIS/SPR detection. Sens. Actuators B Chem. 2011, 159, 178-184. [CrossRef]

40. Zejli, H.; Goud, K.Y.; Marty, J.L. Label free aptasensor for ochratoxin A detection using polythiophene-3-carboxylic acid. Talanta 2018, 185, 513-519. [CrossRef]

41. Liu, R.J.; Wu, H.; Lv, L.; Kang, X.J.; Cui, C.B.; Feng, J.; Guo, Z.J. Fluorometric aptamer based assay for ochratoxin A based on the use of exonuclease III. Microchim. Acta 2018, 185, 254. [CrossRef] [PubMed]

42. Song, C.X.; Hong, W.W.; Zhang, X.Y.; Lu, Y. Label-free and sensitive detection of Ochratoxin A based on dsDNA-templated copper nanoparticles and exonuclease-catalyzed target recycling amplification. Analyst 2018, 143, 1829-1834. [CrossRef] [PubMed]

43. Xia, X.; Wang, H.; Yang, H.; Deng, S.; Deng, R.; Dong, Y.; He, Q. Dual-Terminal Stemmed Aptamer Beacon for Label-Free Detection of Aflatoxin B-1 in Broad Bean Paste and Peanut Oil via Aggregation-Induced Emission. J. Agric. Food Chem. 2018, 66, 12431-12438. [CrossRef]

44. Wang, S.; Zhang, Y.J.; Pang, G.S.; Zhang, Y.W.; Guo, S.J. Tuning the Aggregation/Disaggregation Behavior of Graphene Quantum Dots by Structure-Switching Aptamer for High-Sensitivity Fluorescent Ochratoxin A Sensor. Anal. Chem. 2017, 89, 1704-1709. [CrossRef] [PubMed]

Publisher's Note: MDPI stays neutral with regard to jurisdictional claims in published maps and institutional affiliations.

(C) 2020 by the authors. Licensee MDPI, Basel, Switzerland. This article is an open access article distributed under the terms and conditions of the Creative Commons Attribution (CC BY) license (http://creativecommons.org/licenses/by/4.0/). 